\title{
Optimal Operation Solution for Public Bicycles Based on Genetic Algorithm
}

\author{
Pinhong Zeng \\ Faculty of Economics and Business Administration, Yibin University, Yibin 644000, China; \\ Email: 2004114002@yibinu.edu.cn

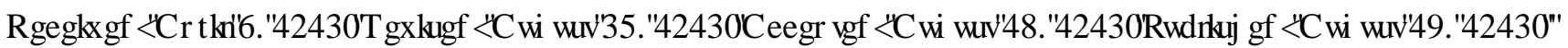

\begin{abstract}
Aiming at the various problems with the scheduling of urban public bicycles, this paper conducted a research on the shortest path between rental points and employed the Floyd algorithm to find the optimal route. Based on the conditions of limited number of bicycle transportation vehicles and in different time slots the bicycle rental points were required to restore to the original number of bicycles, a constraint scheduling model was established according to the bicycle supply-demand relationships of the rental points, and the Genetic Algorithm (GA) was used to solve the model to find the shortest path. In terms of balancing the bicycles at each rental point, this paper re-distributed the initial bicycles according to the different demands of each rental point in different time slots, and solved the problem using the solution of the first problem to obtain the optimal vehicle route. This research is a useful reference for solving difficulties in public bicycle scheduling.
\end{abstract}

Keywords-Linear programming, Shortest path, Floyd algorithm, Minimum spanning tree (MST), Genetic algorithm (GA).

\section{INTRODUCTION}

Existing studies on the layout of public bicycle rental points are mainly qualitative analysis from macroscopic perspectives, they tend to focus more on the layout principle, feature analysis, and scale prediction, and there are few quantitative studies or models. Li et al. [1] divided the rental points into five types: bus stop points, public building points, residential area points, recreational site points, and campus points, and it pointed out that the scale of residential area points should be of similar size with the scale of bus stop points, public building points, and campus points. Zhai et al. [2] established a Markov chain model of urban public bicycle rental system to solve the necessary service capacity of each station. Geng et al. [3] determined the number and scale of public bicycle rental points in Paris by district partition and calculating the average number of trips in each district. Lin and Yang [4] considered the service level as a factor that can affect the layout of public bicycle rental points. Wei et al. [5] analyzed the road network density and service range required by the $(B+R)$ transfer mode. Martens [6] studied the cases of 3 European cities and proposed the travel distance and purpose of public bicycles and the mutual influence between public bicycles and cars. From the perspectives of the travel demand of residents and the supply of traffic facilities, this paper established an optimization model for the layout of urban public bicycle rental points based on two-tier planning, in the hopes of providing a scientific basis for the layout of public bicycle rental points.

Regarding the scheduling of public bicycles in cities, existing studies can be divided into two types, static scheduling, and dynamic scheduling. In terms of static scheduling, Liu et al. [7] constructed a public bicycle system scheduling model with transportation cost minimization as the objective, they used the simulated annealing algorithm to solve the model and obtained a static scheduling scheme of public bicycle system. Scholars Benchimol et al. [8] and Chemla et al. [9] assumed that the bicycle inventory of each rental point in the urban public bicycle system was fixed, that is, under the condition of known scheduling demand, they took transportation cost minimization as the objective to perform public bicycle scheduling. Erdoğan et al. [10] studied the static rebalancing allocation problem of the public bicycle system, and determined the scheduling sequence of the stations with scheduling cost minimization as the objective, and a dispatch vehicle was arranged to collect the public bicycles and deliver them to each station. However, in reality, due to the mobility of public bicycles, the scheduling of public bicycles should be a dynamic scheduling problem, and static mode research cannot give accurate prediction results, and such research results are lagging.

Afterwards, a series of researches have been carried out on the dynamic scheduling of public bicycles, for example, Dong et al. [11] focused the problem of the imbalanced temporal and 
spatial distribution of public bicycles in the public slow-traffic system, and researched the dynamic features of rental point demand during public slow-traffic system scheduling and its fuzzy time window constraints, with rental point satisfaction maximization as the objective, they constructed a public slow-traffic system scheduling model and obtained dynamic scheduling scheme, thereby realizing the dynamic scheduling of the public slow-traffic system. Zuo et al. [12] combined the improved multi-objective Genetic Algorithm (GA) and departure time adjustment The whole procedure, put forward the city bus dispatching method. Steinzen et al. [13] proposed a hybrid evolutionary algorithm to solve the multi-vehicle integrated vehicle and unit scheduling problem in public transportation. Evolutionary algorithms use Lagrange heuristics based on column generation to calculate the fitness of individuals. Jozefowiez et al. [14] proposed a classical multi-objective operator evolutionary algorithm based on meta-heuristic methods to solve the dual-objective vehicle routing problem. Caggiani and Ottomanelli [15] proposed a dynamic bicycle redistribution simulation model, whose purpose is to minimize the scheduling cost of bicycle operators while taking user satisfaction into consideration. Wu et al. [16] studied the priority, dynamic demand features, and service time window of self-service point scheduling in the public bicycle scheduling process, and established a multi-objective optimization model of public bicycle system dynamic scheduling that balances user satisfaction and enterprise scheduling costs, they also designed a hybrid algorithm of tabu algorithm and GA to solve to the dynamic scheduling model. Zhang et al. [17] established a public bicycle scheduling route optimization model based on rolling time domain, but the model did not consider the impact of the time of loading and unloading bicycles on the entire scheduling time, and the results are not completely reliable.

In real life, the number of public bicycles at each rental point is changing all the time, the corresponding demand is changing accordingly, and in different time slots, the rental points that need to be scheduled are different as well, all these complex situations constitute the dynamics in the public bicycle scheduling problem. Therefore, the scheduling schemes must be formulated according to different dynamic features. In order to complete the public bicycle scheduling tasks in a timely and accurate manner, professionals are required to optimize the bicycle dispatch vehicle scheduling to meet people's travel demand, however, unreasonable path selection of the dispatch vehicle will lead to waste of time and resource, so we need effective schemes that can achieve dynamic balance, people can rent bicycles wherever they need, and this would attract more people to choose low-carbon travel method.
With a city $\mathrm{X}$ in China as the study case, this paper established a mathematical planning model with the distance between rental points and the supply-demand relationship of

public bicycles at each rental point as the key points, then GA was employed to solve the model and give the optimized scheduling scheme, thereby obtaining the optimal path of the dispatch vehicle.

\section{EXISTING PROBLEMS In PUBLIC BICYCLE SCHEDUling}

A. Description of problems existing in public bicycle scheduling

The scheduling of public bicycles is that, based on the initial number of bicycles at each rental point and the layout of the rental points, the number of bicycles at each rental point changes after half a day of use, some rental points have more bicycles, while for some rental points, there're too few bicycles left, which can affect the bicycle rental of subsequent users, and people who need to use public bicycles will have to spend more time waiting, therefore, it's necessary to use dispatch vehicles to restore the original number of bicycles at each rental point to facilitate the use of people.

This paper aims to optimize the traveling route of the dispatch vehicle and plan the path with the shortest distance for it, in such case, it'll save time and fuel, realize fast scheduling, and be friendly to the environment, for these purposes, this study attempts to build relevant mathematical model and give the optimized solution.

\section{B. Introduction of existing problems in public bicycle scheduling}

Problem 1: after half a day of bicycle use, the situations of bicycles at each rental point are listed in Table 1, assume there's a dispatch vehicle that can restore the bicycles at each rental point to its original number (20 bicycles at each rental point), then, what is the optimal scheduling plan (shortest path) for the dispatch vehicle?

Problem 2: according to the daily operating information of the public bicycles, high or low, different rental points have different demands, the situations are shown in Table 2 and Table 3, then how to schedule to meet the new bicycle demand?

\section{Analysis of existing problems in public bicycle scheduling}

First, determine the distance and driving route between each rental point, and use the Floyd algorithm to find the shortest driving distance between each two rental points.

TABLE I

SITUATIONS OF BICYCLES AT EACH RENTAL POINT AFTER BICYCLE USE OF 7:00-9:00AM TIME SLOT

\begin{tabular}{|c|c|c|c|c|c|c|c|c|c|c|c|c|c|c|c|}
\hline Rental point & 1 & 2 & 3 & 4 & 5 & 6 & 7 & 8 & 9 & 10 & 11 & 12 & 13 & 14 & 15 \\
\hline Initial number of bicycles & 20 & 20 & 20 & 20 & 20 & 20 & 20 & 20 & 20 & 20 & 20 & 20 & 20 & 20 & 20 \\
\hline Rent out & 5 & 7 & 15 & 15 & 8 & 20 & 15 & 9 & 6 & 5 & 16 & 21 & 1 & 3 & 17 \\
\hline
\end{tabular}


INTERNATIONAL JOURNAL OF CIRCUITS, SYSTEMS AND SIGNAL PROCESSING

\begin{tabular}{|c|c|c|c|c|c|c|c|c|c|c|c|c|c|c|c|}
\hline Returned & 2 & 10 & 7 & 4 & 6 & 6 & 2 & 15 & 25 & 29 & 10 & 6 & 11 & 23 & 7 \\
\hline Left & 17 & 23 & 12 & 9 & 18 & 6 & 7 & 26 & 39 & 44 & 14 & 5 & 30 & 40 & 10 \\
\hline
\end{tabular}

TABLE II

SITUATIONS OF BICYCLES AT EACH RENTAL POINT AFTER BICYCLE USE OF 11:00AM-14:00PM TIME SLOT

\begin{tabular}{|c|c|c|c|c|c|c|c|c|c|c|c|c|c|c|c|}
\hline Rental point & 1 & 2 & 3 & 4 & 5 & 6 & 7 & 8 & 9 & 10 & 11 & 12 & 13 & 14 & 15 \\
\hline Initial number of bicycles & 20 & 20 & 20 & 20 & 20 & 20 & 20 & 20 & 20 & 20 & 20 & 20 & 20 & 20 & 20 \\
\hline Rent out & 6 & 6 & 2 & 10 & 9 & 1 & 2 & 4 & 15 & 6 & 2 & 2 & 11 & 11 & \\
\hline Returned & 5 & 3 & 5 & 3 & 3 & 6 & 7 & 11 & 3 & & 10 & 7 & 10 & 3 & 11 \\
\hline Left & 19 & 17 & 23 & 13 & 14 & 25 & 25 & 27 & 8 & 14 & 28 & 25 & 19 & 12 & 31 \\
\hline
\end{tabular}

TABLE III

SITUATIONS OF BICYCLES AT EACH RENTAL POINT AFTER BICYCLE USE OF 17:00-14:00PM TIME SLOT

\begin{tabular}{|c|c|c|c|c|c|c|c|c|c|c|c|c|c|c|c|}
\hline Rental point & 1 & 2 & 3 & 4 & 5 & 6 & 7 & 8 & 9 & 10 & 11 & 12 & 13 & 14 & 15 \\
\hline Initial number of bicycles & 20 & 20 & 20 & 20 & 20 & 20 & 20 & 20 & 20 & 20 & 20 & 20 & 20 & 20 & 20 \\
\hline Rent out & 5 & 3 & 6 & & 12 & 7 & 5 & 14 & 30 & 24 & 4 & 6 & 17 & 22 & 10 \\
\hline Returned & 8 & 5 & 16 & 15 & 8 & 27 & 16 & 1 & 10 & 4 & 9 & 25 & 6 & 2 & 7 \\
\hline Left & 23 & 22 & 30 & 35 & 16 & 40 & 31 & 7 & 0 & 0 & 25 & 39 & 9 & 0 & 23 \\
\hline
\end{tabular}

For Problem 1, calculate the supply and demand of each rental point according to the number of left bicycles after a period of time, and use the shortest path obtained in above steps to establish the 0-1 constraint scheduling model, and then use GA to solve model and obtain the optimal solution, namely the driving route of the dispatch vehicle.

For Problem 2, redistribute the bicycles according to the use frequency of each rental point, allocate more bicycles to rental points with more rent out bicycles, and allocate less bicycles to rental points with more returned bicycles, in this way, under the condition without timely scheduling, it'll enable as many people as possible to use the bicycles, then, solve the model using the same method as Problem 1, and obtain the optimal scheduling route.

D. Model symbols

\begin{tabular}{|c|l|}
\hline Symbol & \multicolumn{1}{|c|}{ Description } \\
\hline $\mathrm{G}=(\mathrm{A}, \mathrm{E})$ & Network of dispatch vehicle of public bicycles \\
\hline $\mathrm{A}$ & Collection of all rental points \\
\hline $\mathrm{E}$ & Collection of paths between rental points \\
\hline $\mathrm{B}$ & $\begin{array}{l}\text { Collection of rental points with redundant bicycles } \\
\text { (supply points) }\end{array}$ \\
\hline $\mathrm{D}$ & $\begin{array}{l}\text { Collection of rental points with insufficient bicycles } \\
\text { (demand points) }\end{array}$ \\
\hline $\mathrm{V}_{\mathrm{ij}}$ & $\begin{array}{l}\text { Number of bicycles on the dispatch vehicle when it } \\
\text { travels from point } \mathrm{i} \text { to point } \mathrm{j}\end{array}$ \\
\hline $\mathrm{V}_{\max }$ & The maximum load of dispatch vehicle \\
\hline $\mathrm{b}_{\mathrm{i}}$ & The supply amount of supply point $\mathrm{i}$ \\
\hline $\mathrm{d}_{\mathrm{i}}$ & The demand amount of demand point $\mathrm{i}$ \\
\hline $\mathrm{Z}_{\mathrm{i}}$ & $\begin{array}{l}\text { Total supply amount of all supply points (it is also the } \\
\text { total demand amount) }\end{array}$ \\
\hline
\end{tabular}

\begin{tabular}{|c|l|}
\hline $\mathrm{W}_{\mathrm{ij}}$ & The driving route from rental point $\mathrm{i}$ to rental point $\mathrm{j}$ \\
\hline $\mathrm{C}_{\mathrm{ij}}=\{0,1\}$ & $\begin{array}{l}1(0) \text { represents there is (isn't) supply-demand } \\
\text { relationship from } \mathrm{i} \text { to } \mathrm{j}\end{array}$ \\
\hline
\end{tabular}

\section{E. Model assumptions}

(1) The red-light waiting time is not considered;

(2) The vehicle travels at a constant speed;

(3) The time it takes to load and unload bicycles from the dispatch vehicle at each rental point is the same;

(4) All rental points can receive infinite number of returned bicycles;

(5) The dispatch center is near rental point 1 ;

(6) The initial number of bicycles at each rental point is the same, each has and only has 20 bicycles;

(7) The maximum load of dispatch vehicle is 30 bicycles;

(8) Considering the road and traffic conditions, the driving speed of the dispatch vehicle is set to be $30 \mathrm{~km} / \mathrm{h}$.

\section{MODEL CONSTRUCTION}

\section{A. Model analysis}

Before constructing the model with the driving distance minimization of dispatch vehicle as the objective, the Floyd algorithm was used to get the shortest distances between rental points according to the geographical location of each rental point, and then the model of rental points with different demands for public bicycles was built.

The shortest paths between the 15 rental points obtained by the algorithm are shown in Table 4.

\section{TABLE IV}

SHORTEST PATHS BETWEEN ANY TWO RENTAL POINTS

\begin{tabular}{|c|c|c|c|c|c|c|c|c|c|c|c|c|c|c|c|}
\hline Rental point & 1 & 2 & 3 & 4 & 5 & 6 & 7 & 8 & 9 & 10 & 11 & 12 & 13 & 14 & 15 \\
\hline 1 & 0 & 950 & 620 & 1200 & 1070 & 1400 & 1900 & 1680 & 2500 & 2680 & 650 & 1410 & 1570 & 2270 & 2540 \\
\hline 2 & 950 & 0 & 720 & 1860 & 1740 & 1050 & 2420 & 2180 & 2760 & 2310 & 500 & 1250 & 1200 & 1840 & 2150 \\
\hline
\end{tabular}


INTERNATIONAL JOURNAL OF CIRCUITS, SYSTEMS AND SIGNAL PROCESSING

\begin{tabular}{|c|c|c|c|c|c|c|c|c|c|c|c|c|c|c|c|}
\hline 3 & 620 & 720 & 0 & 1160 & 1130 & 800 & 1960 & 1720 & 1650 & 1260 & 1230 & 1210 & 960 & 1650 & 1940 \\
\hline 4 & 1200 & 1860 & 1160 & 0 & 1630 & 1940 & 1160 & 1650 & 1950 & 2360 & 1770 & 2650 & 2140 & 2300 & 1640 \\
\hline 5 & 1070 & 1740 & 1130 & 1630 & 0 & 730 & 820 & 510 & 1410 & 1650 & 1760 & 2210 & 1540 & 1180 & 1840 \\
\hline 6 & 1400 & 1050 & 800 & 1940 & 730 & 0 & 1420 & 1190 & 1650 & 1240 & 1570 & 1530 & 850 & 810 & 1580 \\
\hline 7 & 1900 & 2420 & 1960 & 1160 & 820 & 1420 & 0 & 710 & 940 & 1530 & 2010 & 2340 & 2210 & 1400 & 2160 \\
\hline 8 & 1680 & 2180 & 1720 & 1650 & 510 & 1190 & 710 & 0 & 810 & 1100 & 2330 & 2660 & 2000 & 700 & 1450 \\
\hline 9 & 2500 & 2760 & 1650 & 1950 & 1410 & 1650 & 940 & 810 & 0 & 400 & 2670 & 2650 & 2130 & 850 & 1170 \\
\hline 10 & 2680 & 2310 & 1260 & 2360 & 1650 & 1240 & 1530 & 1100 & 400 & 0 & 2500 & 2360 & 2130 & 440 & 730 \\
\hline 11 & 650 & 500 & 1220 & 1770 & 1760 & 1570 & 2010 & 2330 & 2670 & 2500 & 0 & 730 & 1380 & 2410 & 2360 \\
\hline 12 & 1360 & 1230 & 1210 & 2650 & 2210 & 1530 & 2340 & 2660 & 2650 & 2360 & 730 & 0 & 660 & 2330 & 3010 \\
\hline 13 & 1570 & 1200 & 960 & 2140 & 1540 & 850 & 2210 & 2000 & 2130 & 2130 & 1380 & 660 & 0 & 1690 & 1110 \\
\hline 14 & 2270 & 1840 & 1650 & 2300 & 1180 & 810 & 1400 & 700 & 850 & 440 & 2410 & 2330 & 1690 & 0 & 740 \\
\hline 15 & 2540 & 2150 & 1940 & 1640 & 1840 & 1580 & 2160 & 1450 & 1170 & 730 & 2360 & 3010 & 1110 & 740 & 0 \\
\hline
\end{tabular}

Regarding Problem 1, a dispatch vehicle is arranged to drive from the dispatch center to distribute the bicycles, its aim is to find a shortest path under the condition that the scheduling is completed. $\mathrm{C}_{\mathrm{ij}}$ and 0-1 variables represent whether the dispatch vehicle travels from rental point $i$ to rental point $j$, that is:

\section{$C_{i j}=\left\{\begin{array}{l}1 \text {, indicates that the dispatch vehicle travels from rental point } \mathrm{i} \text { to rental point } \mathrm{j} \\ 0 \text {, indicates that the dispatch vehicle doesn't travel from rental point } \mathrm{i} \text { to rental point } \mathrm{j}\end{array}\right.$}

According to the situations of the rental points, a few constraints are assigned to the number of times the dispatch vehicle passes through the rental points and the number of bicycles on the dispatch vehicle so that the dispatch vehicle passes through each demand point and supply point only once, and the number of bicycles on the dispatch vehicle at any time does not exceed the load limit, also, during the driving process of the dispatch vehicle, the driving direction should be considered as well. This problem is similar to the TSP problem, which is a NP-hard problem, and it's difficult to obtain the optimal solution. GA can be adopted to search for the solution with driving distance minimization of the dispatch vehicle as the objective, and obtain the optimal driving route.

\section{B. Model construction}

(1) Objective function analysis

In this model, the primary consideration is time optimization, but in the model assumptions, it's assumed that the stop time of the dispatch vehicle at each rental point is the same, however, according to actual survey results, the dispatch vehicle has to stop at almost every rental point, therefore the time optimization problem is converted to the distance minimization problem, and the distance $S$ is equal to the sum of the shortest distance of all driving routes.

The objective function represents the shortest path taken by the dispatch vehicle, that is:

$$
\min S=\sum_{i \in A} \sum_{j \in A} C_{i j} W_{i j} \quad, i \neq j
$$

\section{(2) Condition analysis}

Survey results reveal that the number of bicycles at each rental point does not exceed 50, based on the assumption that the number of bicycles at each rental points needs to be restored to 20 , the demand of the rental points is generally between -30 and +20 (- represents transfer-out, + represents transfer-in), so, any dispatch vehicle can meet the requirement, and it's stipulated that the scheduling only performs once at each rental point, namely:

(1) If there's behavior from rental point $\mathrm{x}$ to rental point $\mathrm{y}$, and the behavior only performs once, then:

$\begin{cases}\sum_{\mathrm{i} \in \mathrm{A}} C_{i j}=1 & , j \in D \\ \sum_{j \in \mathrm{A}} C_{i j}=1 & , i \in D \\ \sum_{i \in A} C_{i j}=\sum_{i \in A} C_{j i}=1 & , j \in B\end{cases}$

(2) When the dispatch vehicle arrives at a demand point, the public bicycles on the dispatch vehicle must meet the number of vehicles required by this point, so when the number of bicycles on the vehicle cannot meet the requirement of this demand point, the vehicle will not pass through this point.

$\sum_{i \in A} C_{i j}\left(V_{i j}-d_{j}\right) \geq 0 \quad, j \in D$

(3) When the dispatch vehicle arrives at a supply point, it collects all the surplus bicycles of the supply point. If the remaining space of the dispatch vehicle cannot meet the requirement, the vehicle will not pass through this point.

$\sum_{i \in A} C_{i j}\left(V_{i j}+b_{j}\right) \leq V_{\max } \quad, j \in B$

In addition, it should also satisfy that the number of surplus bicycles collected by the dispatch vehicle from all supply points is equal to the supply amount of all supple points, and verify whether the dispatch vehicle has collected too few or too many 
bicycles.

$$
\sum_{i \in A} C_{i j} b_{j}=z_{j} \quad, j \in B
$$

The minimum and maximum loads of the dispatch vehicle are restricted to

$0 \leq V_{i j} \leq V_{\max }$

Use the solution of the model to constrain and establish the following model:

$$
\begin{array}{cc}
\min S=\sum_{i \in A} \sum_{j \in A} C_{i j} W_{i j} & , i \neq j \\
\text { s.t. } \begin{cases}\sum_{i \in \mathrm{A}} C_{i j}=1 & , j \in D \\
\sum_{i \in A} C_{i j}=\sum_{i \in A} C_{j i}=1 & , i \in D \\
\sum_{i \in A} C_{i j}=\sum_{i \in A} C_{j i}=1 & , j \in B \\
\sum_{i \in A} C_{i j}\left(V_{i j}-d_{j}\right) \geq 0 & , j \in D \\
\sum_{i \in A}\left(V_{i j}+b_{j}\right) \leq V_{\max } & , j \in B \\
\sum_{i \in A} C_{i j} b_{j}=z_{j} & , j \in B \\
0 \leq V_{i j} \leq V_{\max } & , i, j \in A \\
C_{i j}=\{0,1\} & \end{cases}
\end{array}
$$

\section{MODEL SOLUTION}

Assume the demand of each rental point after the bicycle use of time slot 7:00-9:00am is shown in Table 5.

\section{A. $G A$}

(1) Introduction to GA

After analyzing the relevant survey data, this study employed GA to solve the problem, GA is an intelligent optimization method commonly-used in engineering design, operations research, and other fields, and it can be used as a search algorithm for complex system optimization.

As a global optimization algorithm, GA originated from the phenomenon of survival of the fittest in nature. It simulates the selection, crossover, and mutation operations of a population composed of chromosomes in the process of reproduction. According to certain rules, after the reproduction of each generation, the chromosomes retain the optimal gene individual in the population to the next generation to achieve of the goal natural evolution and obtain the optimal solution.

In summary, regarding the problem to be solve by GA in this study, here are a few considerations, first, establish the fitness function, and its objective function is the distance traveled by the dispatch vehicle. According to actual conditions and corresponding relationships, it can be known that the number of bicycles left at the rental points is the decision variable, and the rest variables are functions of the decision variable. In the solution process, the aim is to reduce the driving distance of the dispatch vehicle during the scheduling process.

(2) Pro and cons of the algorithm

Pros: (1) GA is widely used in various fields and it has many applications in real life, such as the classical multi-model and multi-objective function optimization, the hard and complex combinatorial optimization, and the workshop scheduling problems that can reflect the design of classical intelligent algorithms. (2) GA has strong robustness, it can be run multiple times on the computer without crashing the system, and it can reduce the deviation of results caused by model assumptions.

Cons: (1) Large search range (2) Low efficiency (3) Largely dependent on the initial population.

(3) Flow of GA

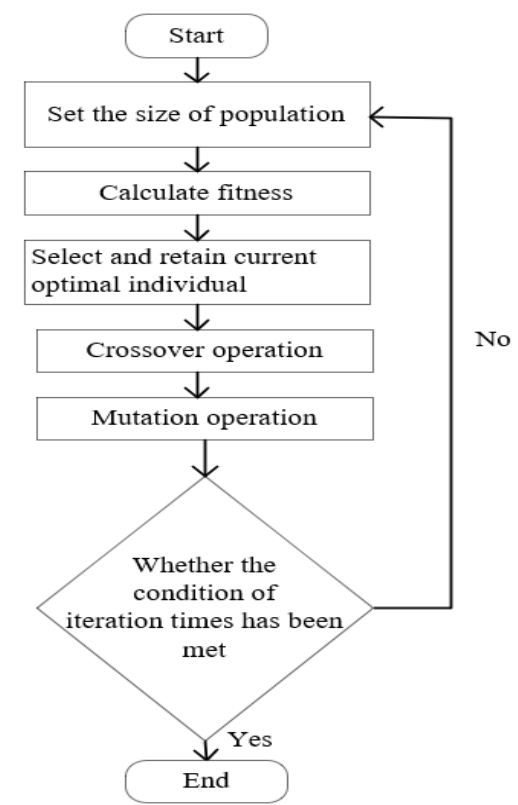

Fig. 1 Flow of GA

\section{B. Problem solving}

\section{(1) Solution of Problem 1}

GA was used to solve the model and the obtained traveling route of the dispatch vehicle is: $1-2-1-13-3-5-8-9-7$ $-4-10-15-6-14-12-11$. The total distance traveled is 17.52 kilometers and the time taken is 35.04 minutes. See the specific scheduling arrangements in Table 6.

TABLE V

DEMAND OF EACH RENTAL POINT AFTER BICYCLE USE OF TIME SLOT 7:00-9:00AM

\begin{tabular}{|l|l|l|l|l|l|l|l|l|l|l|l|l|l|l|l|} 
Rental point & 1 & 2 & 3 & 4 & 5 & 6 & 7 & 8 & 9 & 10 & 11 & 12 & 13 & 14 & 15 \\
\hline
\end{tabular}


INTERNATIONAL JOURNAL OF CIRCUITS, SYSTEMS AND SIGNAL PROCESSING

\begin{tabular}{|c|c|c|c|c|c|c|c|c|c|c|c|c|c|c|c|}
\hline Bicycle left & 17 & 23 & 12 & 9 & 18 & 6 & 7 & 26 & 39 & 44 & 14 & 5 & 30 & 40 & 10 \\
\hline Estimated demand & 20 & 20 & 20 & 20 & 20 & 20 & 20 & 20 & 20 & 20 & 20 & 20 & 20 & 20 & 20 \\
\hline Number of bicycles needs to be transferred out & 3 & & 8 & 11 & 2 & 14 & 13 & & & & 6 & 15 & & & 10 \\
\hline Number of bicycles needs to be transferred in & & 3 & & & & & & 6 & 19 & 24 & & & 10 & 20 & \\
\hline
\end{tabular}

TABLE VI

\section{SPECIFIC SCHEDULING ARRANGEMENTS}

\begin{tabular}{|c|c|c|c|c|c|c|c|c|c|c|c|c|c|c|c|c|}
\hline Route of the dispatch vehicle & 1 & 2 & 1 & 13 & 3 & 5 & 8 & 9 & 7 & 4 & 10 & 15 & 6 & 14 & 12 & 11 \\
\hline $\begin{array}{c}\text { Number of bicycles at rental points } \\
\text { before scheduling }\end{array}$ & 17 & 23 & 17 & 30 & 12 & 18 & 26 & 39 & 7 & 9 & 44 & 10 & 6 & 40 & 5 & 14 \\
\hline Number of bicycles need to be scheduled & +3 & -3 & +3 & -10 & +8 & +2 & -6 & -19 & +13 & +11 & -24 & +10 & +14 & -20 & +15 & +6 \\
\hline $\begin{array}{c}\text { Number of bicycles on the dispatch } \\
\text { vehicle }\end{array}$ & 0 & 3 & 0 & 10 & 2 & 0 & 6 & 25 & 12 & 1 & 25 & 15 & 1 & 21 & 6 & 0 \\
\hline $\begin{array}{c}\text { Number of bicycles at rental points after } \\
\text { scheduling }\end{array}$ & 17 & 20 & 20 & 20 & 20 & 20 & 20 & 20 & 20 & 20 & 20 & 20 & 20 & 20 & 20 & 20 \\
\hline
\end{tabular}

Result optimization: according to the description of the problem it's known that the dispatch center is near rental point No.1, in the results obtained from this scheduling method, the scheduling is finished when the dispatch vehicle travels to rental point No.11, but the empty dispatch vehicle needs to return to rental point No.1 to park, at this time, plus the distance from rental point No.11 to rental point No.1, the driving distance of the dispatch vehicle is 18.17 kilometers in total, and the total time consumption is 36.34 minutes.

Because the dispatch vehicle must return to rental point No.1 to park, in the solution process, we may delete rental point No.1 after the dispatch vehicle starts from it, and then after solution, manually adds the route from the last rental point to rental point No. 1 , then the driving route is $1-2-13-3-5-8-9-7-4$ $-10-15-6-14-12-11-1$, the total driving distance is 16.85 kilometers and the total time consumption is 33.70 minutes, compare with the directly obtained solution, the distance is 1320 meters shorter, the specific scheduling arrangements are listed in Table 7.

TABLE VII

SPECIFIC SCHEDULING ARRANGEMENTS AFTER OPTIMIZATION

\begin{tabular}{|c|c|c|c|c|c|c|c|c|c|c|c|c|c|c|c|c|}
\hline Route of the dispatch vehicle & 1 & 2 & 13 & 3 & 5 & 8 & 9 & 7 & 4 & 10 & 15 & 6 & 14 & 12 & 11 & 1 \\
\hline $\begin{array}{c}\text { Number of bicycles at rental points } \\
\text { before scheduling }\end{array}$ & 17 & 23 & 30 & 12 & 18 & 26 & 39 & 7 & 9 & 44 & 10 & 6 & 40 & 5 & 14 & 17 \\
\hline Number of bicycles need to be scheduled & +3 & -3 & -10 & +8 & +2 & -6 & -19 & +13 & +11 & -24 & +10 & +14 & -20 & +15 & +6 & +3 \\
\hline $\begin{array}{c}\text { Number of bicycles on the dispatch } \\
\text { vehicle }\end{array}$ & 0 & 3 & 13 & 5 & 3 & 9 & 28 & 15 & 4 & 28 & 18 & 4 & 24 & 9 & 3 & 0 \\
\hline $\begin{array}{c}\text { Number of bicycles at rental points after } \\
\text { scheduling }\end{array}$ & 17 & 20 & 20 & 20 & 20 & 20 & 20 & 20 & 20 & 20 & 20 & 20 & 20 & 20 & 20 & 20 \\
\hline
\end{tabular}

\section{(2) Solution of Problem 2}

The survey reveals that within a day, 7:00-9:00am and 17:00-20:30pm are the peak hours for the use of public bicycles, the use of bicycles between 11:00-14:00 is fewer than the morning and evening hours, in the rest time slots, the use of bicycles is much less and can be ignored; therefore, it we want to meet people's demand for public bicycles for the day, the dispatch vehicle needs to finish scheduling between 9:30-10:30 in the morning and between 15:30-16:30 in the afternoon, and perform scheduling again after $21: 00 \mathrm{pm}$ to guarantee the use of bicycles in the next morning. Influenced by working hours, Chinese people use bicycles more in the morning, middle and evening.According to this scheduling method, the dispatch vehicle needs to perform the scheduling task three times a day to meet people' daily traveling requirement.

Table 8 and Table 9 give the situations of each rental point after bicycle use of the 11:00-14:00 and 17:00-20:30 time slots.

According to the solution method of Problem 1, after the bicycle use of the 11:00-14:00 time slot, the route arrangement of the dispatch vehicle is $1-3-2-11-12-13-6-5-8-14$ $-10-15-9-7-4-1$. The driving distance of this route arrangement is 11.66 kilometers and its takes 23.32 minutes. Similarly, after the bicycle use of the 17:00-20:30 time slot, the route arrangement of the dispatch vehicle is $1-3-2-11-13$ $-12-5-8-7-9-15-6-14-4-10-1$. The driving distance of this route arrangement is 17.67 kilometers and its takes 35.34 minutes.

TABLE VIII

SITUATIONS OF EACH RENTAL POINT AFTER BICYCLE USE OF THE 11:00-14:00 TIME SLOT 
INTERNATIONAL JOURNAL OF CIRCUITS, SYSTEMS AND SIGNAL PROCESSING

\begin{tabular}{|c|c|c|c|c|c|c|c|c|c|c|c|c|c|c|c|}
\hline Rental point & 1 & 2 & 3 & 4 & 5 & 6 & 7 & 8 & 9 & 10 & 11 & 12 & 13 & 14 & 15 \\
\hline Number of bicycles left & 19 & 17 & 23 & 13 & 14 & 25 & 25 & 27 & 8 & 14 & 28 & 25 & 19 & 12 & 31 \\
\hline Estimated demand & 20 & 20 & 20 & 20 & 20 & 20 & 20 & 20 & 20 & 20 & 20 & 20 & 20 & 20 & 20 \\
\hline Number of bicycles that need to be transferred in & 1 & 3 & & 7 & 6 & & & & 12 & 6 & & & 1 & 8 & \\
\hline Number of bicycles that need to be transferred out & & & 3 & & & 5 & 5 & 7 & & & 8 & 5 & & & 11 \\
\hline
\end{tabular}

TABLE IX

SITUATIONS OF EACH RENTAL POINT AFTER BICYCLE USE OF THE 17:00-20:30 TIME SLOT

\begin{tabular}{|c|c|c|c|c|c|c|c|c|c|c|c|c|c|c|c|}
\hline Rental point & 1 & 2 & 3 & 4 & 5 & 6 & 7 & 8 & 9 & 10 & 11 & 12 & 13 & 14 & 15 \\
\hline Number of bicycles left & 23 & 22 & 30 & 35 & 16 & 40 & 31 & 7 & 0 & 0 & 25 & 39 & 9 & 0 & 23 \\
\hline Estimated demand & 20 & 20 & 20 & 20 & 20 & 20 & 20 & 20 & 20 & 20 & 20 & 20 & 20 & 20 & 20 \\
\hline Number of bicycles that need to be transferred in & & & & & 4 & & & 13 & 20 & 20 & & & 11 & 20 & \\
\hline Number of bicycles that need to be transferred out & 3 & 2 & 10 & 15 & & 20 & 11 & & & & 5 & 19 & & & 3 \\
\hline
\end{tabular}

Therefore, according to the scheduling arrangements of each rental point, the driving distance of the dispatch vehicle in a day is 46.18 kilometers, which takes 92.36 minutes.

In this study, the number of bicycles placed at each rental point is adjusted according to the different use amounts at different rental points in different time slots, and the redistribution results are shown in Table 10. After redistribution, the left bicycles at each rental point after the bicycle use of two time slots are shown in Table 11 and Table 12.

TABLE X

\section{REDISTRIBUTION RESULTS OF BICYCLES}

\begin{tabular}{|c|c|c|c|c|c|c|c|c|c|c|c|c|c|c|c|}
\hline Rental point & 1 & 2 & 3 & 4 & 5 & 6 & 7 & 8 & 9 & 10 & 11 & 12 & 13 & 14 & 15 \\
\hline Initial number of bicycles in the morning & 19 & 17 & 25 & 26 & 20 & 29 & 27 & 15 & 10 & 10 & 23 & 30 & 15 & 10 & 24 \\
\hline Initial number of bicycles in the evening & 14 & 15 & 15 & 13 & 20 & 11 & 11 & 25 & 33 & 38 & 14 & 11 & 30 & 35 & 15 \\
\hline
\end{tabular}

TABLE XI

LEFT BICYCLES AT EACH RENTAL POINT AFTER THE BICYCLE USE OF THE 7:00-9:00 TIME SLOT AFTER REDISTRIBUTION

\begin{tabular}{|c|c|c|c|c|c|c|c|c|c|c|c|c|c|c|c|}
\hline Rental point & 1 & 2 & 3 & 4 & 5 & 6 & 7 & 8 & 9 & 10 & 11 & 12 & 13 & 14 & 15 \\
\hline Initial number of bicycles & 19 & 17 & 25 & 26 & 20 & 29 & 27 & 15 & 10 & 10 & 23 & 30 & 15 & 10 & 24 \\
\hline Rent out & 3 & & 8 & 11 & 2 & 14 & 13 & & & & 6 & 15 & & & 10 \\
\hline Returned & & 3 & & & & & & 6 & 19 & 24 & & & 10 & 20 & \\
\hline Left & 16 & 20 & 17 & 15 & 18 & 15 & 14 & 21 & 29 & 34 & 17 & 15 & 25 & 30 & 14 \\
\hline
\end{tabular}

TABLE XII

Left bicycles at each rental point after the bicycle use of the 11:00-14:00 time slot after redistribution

\begin{tabular}{|c|c|c|c|c|c|c|c|c|c|c|c|c|c|c|c|}
\hline Rental point & 1 & 2 & 3 & 4 & 5 & 6 & 7 & 8 & 9 & 10 & 11 & 12 & 13 & 14 & 15 \\
\hline Initial number of bicycles & 16 & 20 & 17 & 15 & 18 & 15 & 14 & 21 & 29 & 34 & 17 & 15 & 25 & 30 & 14 \\
\hline Rent out & 1 & 3 & & 7 & 6 & & & & 12 & 6 & & & 1 & 8 & \\
\hline Returned & & & 3 & & & 5 & 5 & 7 & & & 8 & 5 & & & 11 \\
\hline Left & 15 & 17 & 20 & 8 & 12 & 20 & 19 & 28 & 17 & 28 & 25 & 20 & 24 & 22 & 25 \\
\hline
\end{tabular}

As can be seen from the data in the table, after the bicycle use in the morning, the numbers of bicycles left at each rental point are relatively even, under condition without scheduling, it is still possible that the bicycle use during the noon hours could be met, therefore the scheduling is not necessary, and the rental points could continue to operate.

After the bicycle use in the noon hours, the left bicycles at most rental points can still support normal operation, however, considering that the evening hours are peak hours for bicycle use, especially rental points $4,5,7,9$, and 10 might be near residential areas or office buildings, many people would choose to ride bicycles for their short-distance commute, the left bicycles at these rental points may not be able to support normal operation, therefore, according to the numbers of initial bicycles listed in Table 10, the arrangements are rescheduled as shown in Table 13.

TABLE XIII

SCHEDULING ARRANGEMENTS AFTER BICYCLE USE OF 11:00-14.00 TIME SLOT 
INTERNATIONAL JOURNAL OF CIRCUITS, SYSTEMS AND SIGNAL PROCESSING

\begin{tabular}{|c|c|c|c|c|c|c|c|c|c|c|c|c|c|c|c|}
\hline Rental point & 1 & 2 & 3 & 4 & 5 & 6 & 7 & 8 & 9 & 10 & 11 & 12 & 13 & 14 & 15 \\
\hline Number of left bicycles & 15 & 17 & 20 & 8 & 12 & 20 & 19 & 28 & 17 & 28 & 25 & 20 & 24 & 22 & 25 \\
\hline Estimated demand & 14 & 15 & 15 & 13 & 20 & 11 & 11 & 25 & 33 & 38 & 14 & 11 & 30 & 35 & 15 \\
\hline Number of bicycles that need to be transferred in & & & & 5 & 8 & & & & 16 & 10 & & & 6 & 13 & \\
\hline Number of bicycles that need to be transferred out & 1 & 2 & 5 & & & 9 & 8 & 3 & & & 11 & 9 & & & 10 \\
\hline
\end{tabular}

After calculation, the driving route of the dispatch vehicle is: $1-3-2-11-12-13-14-8-7-5-6-10-15-9-4-$ 1. The total driving distance is 13.46 kilometers, and it takes
26.92 minutes.

The left bicycles at each rental point after the bicycle use of evening peak hours are shown in Table 14.

TABLE XIV

LEFT BICYCLES AFTER BICYCLE USE OF THE 17:00-20:30 TIME SLOT AFTER REDISTRIBUTION

\begin{tabular}{|c|c|c|c|c|c|c|c|c|c|c|c|c|c|c|c|}
\hline Rental point & 1 & 2 & 3 & 4 & 5 & 6 & 7 & 8 & 9 & 10 & 11 & 12 & 13 & 14 & 15 \\
\hline Initial number of bicycles & 14 & 15 & 15 & 13 & 20 & 11 & 11 & 25 & 33 & 38 & 14 & 11 & 30 & 35 & 15 \\
\hline Rent out & & & & & 4 & & & 8 & 20 & 18 & & & 11 & 27 & \\
\hline Returned & 3 & 2 & 10 & 15 & & 20 & 11 & & & & 5 & 19 & & & 3 \\
\hline Left & 17 & 17 & 25 & 28 & 16 & 31 & 22 & 17 & 13 & 20 & 19 & 30 & 19 & 8 & 18 \\
\hline
\end{tabular}

At this time, it is not difficult to see that for most of the rental points, the left bicycles can still support normal operation, however, considering that the next morning is still the peak hours, so the bicycles still need to be scheduled, according to the initial numbers of bicycles listed in Table 10, the scheduling is arranged as shown in Table 15.

TABLE XV

SCHEDULING ARRANGEMENTS AFTER BICYCLE USE OF 17:00-20:30 TIME SLOT

\begin{tabular}{|c|c|c|c|c|c|c|c|c|c|c|c|c|c|c|c|}
\hline Rental point & 1 & 2 & 3 & 4 & 5 & 6 & 7 & 8 & 9 & 10 & 11 & 12 & 13 & 14 & 15 \\
\hline Number of left bicycles & 17 & 17 & 25 & 28 & 16 & 31 & 22 & 17 & 13 & 20 & 19 & 30 & 19 & 8 & 18 \\
\hline Estimated demand & 19 & 17 & 25 & 26 & 20 & 29 & 27 & 15 & 10 & 10 & 23 & 30 & 15 & 10 & 24 \\
\hline Number of bicycles that need to be transferred in & 2 & & & & 4 & & 5 & & & & 4 & & & 2 & 6 \\
\hline Number of bicycles that need to be transferred out & & & & 2 & & 2 & & 2 & 3 & 10 & & & 4 & & \\
\hline
\end{tabular}

After calculation, the driving route of the dispatch vehicle is: $1-4-8-5-6-14-10-9-7-11-13-15-1$. The total driving distance is 13.72 kilometers and it takes 27.44 minutes.

According to above results, if the vehicle is arranged as shown in Table 10, the driving distance of the dispatch vehicle in a day is 27.18 kilometers, and it takes 54.36 minutes.

Compared with the scheduling method that the numbers of bicycles at each rental point are equal, if the numbers of bicycles at each rental point can be scheduled according to the different daily demand of each rental point, then the driving distance of the dispatch vehicle is 19 kilometers shorter, and it can save 38 minutes each day.

\section{Model Evaluation}

\section{Merits of the model}

(1) Based on correct and clear analysis of the data, a reasonable and scientific mathematical planning model has been established.

(2) Actual situations have been considered when establishing the model, and reasonable arrangements were made according to different situations;

(3) In the scheduling process of the public bicycles, not only the driving time of the dispatch vehicle, but also the operation time of the public bicycles should be considered, so the less the times of operations, the more time saved, therefore, in the solution of Problem 2, the number of bicycles that needs to be scheduled has been greatly reduced, which could save more time.

\section{Shortcomings of the model}

(1) The data used in this study came from survey and was idealized, therefore it could not completely cover the real situation; In addition, manual scheduling is mainly used at present, but manual scheduling has no capacity constraints and cannot reasonably allocate existing resources. In order to meet the optimal configuration of the number of vehicles at a rental point, the number of bikes on the dispatching vehicle at a rental point may be negative or exceed the maximum capacity;

(2) For the bicycle arrangements in Problem 2, no corresponding model has been established, it needs long term survey and gradually adjusts the scheduling arrangements of each rental point, Strengthening dynamic study;

(3) In reality, many factors can influence the scheduling arrangements, the model has only considered the driving distance of the dispatch vehicle and the number of bicycles that needs to be scheduled, which is not conducive to the promotion of the model. 


\section{CONCLUSIONS}

Drawing on the knowledge of operations research, mathematical modeling, and algorithm analysis, this paper adopted 0-1 constraint scheduling, Floyd algorithm, and GA to establish a model which can realize the following functions:

(1) Use the Floyd algorithm to find the shortest path between the rental points of public bicycles;

(2) Use the basic principles of GA and survey data to obtain the driving route of the dispatch vehicle and complete the supply-demand relationships of each rental point on the shortest possible route;

(3) Formulate the public bicycle scheduling arrangements based on actual demand of different rental points;

(4) Use mathematical linear programming combined with 0-1 integer constraint scheduling to get the minimum times of vehicle travel and analyze and process the data reasonably, which has improved the accuracy of the model;

(5) The model has good qualities for promotion, and can be used to solve many other scheduling problems.

Through the research and analysis of genetic algorithm, it is concluded that genetic algorithm is more suitable for solving the problem of public bicycle scheduling. According to the constructed public bicycle rental model, the genetic algorithm is used to solve the model, and the feasibility and effectiveness of genetic algorithm in solving the problem of public bicycle resource scheduling and configuration are proved by an example. However, in the actual application process, due to the large number of public bike rental points, in addition, there are also the shortage of public bikes, so the algorithm needs to be further optimized in the process of computing the scheduling scheme.

More than any other algorithm. In future studies, multi-station and multi-vehicle scheduling problems can be discussed, which will be of greater help to improve operational efficiency. The optimization scheme of other intelligent algorithms can also be studied to solve the problem.

\section{REFERENCES}

[1] L.H. Li, H. Chen, and X.L. Sun, "Bike rental station deployment planning in Wuhan", Urban Transport of China, vol. 7, no. 4, pp. 39-44, 2009.

[2] Y. Zhai, J. Liu, J., Du, and H. Wu, "Fleet size and rebalancing analysis of dockless bike-sharing stations based on markov chain", ISPRS International Journal of Geo-Information, vol. 8, no. 8, pp. 334, 2019.

[3] X. Geng, K. Tian, Y. Zhang, and Q. Li, " Bike rental station planning and design in Paris", Urban Transport of China, vol. 7, no. 4, pp. 21-29, 2009

[4] J.R. Lin and T.H. Yang, "Strategic design of public bicycle sharing systems with service level constraints", Transportation Research Part E: Logistics and Transportation Review, vol. 47, no. 2, pp. 284-294, 2011.

[5] Z.H. Wei, H.B. Du, and F.T. Ren, " Research on R\&B trip mode in big cities of China", Road Traffic \& Safety, vol. 5, no. 4, pp. 1-4, 2005.

[6] K. Martens, "The bicycle as a feedering mode: experiences from three European countries", Transportation Research Part D: Transport and Environment, vol. 9, no. 4, pp. 281-294, 2004.

[7] D.T., Liu, W.D., Fang, J.M. Zhang, and M.Z. Guo, "Scheduling algorithm for public bicycle system", Computer Systems and Applications, vol. 20, no. 9, pp. 112-116, 2011.

[8] M. Benchimol, P. Benchimol, B. Chappert, A. De La Taille, F. Laroche, F. Meunier, and L. Robinet, "Balancing the stations of a self service "bike hire" system", RAIRO-Operations Research, vol. 45, no. 1, pp. 37-61, 2011.

[9] D. Chemla, F. Meunier, and R.W. Calvo, "Bike sharing systems: Solving the static rebalancing problem", Discrete Optimization, vol. 10, no. 2, pp. 120-146, 2013

[10] G. Erdoğan, M. Battarra, and R.W. Calvo, "An exact algorithm for the static rebalancing problem arising in bicycle sharing systems", European Journal of Operational Research, vol. 245, no. 3, pp. 667-679, 2015.

[11] H.Z. Dong, J.Y. Zhao, H.F. Guo, and M.F. Guo, "Research on the dynamic model and rolling horizon scheduling algorithm for public-use bicycle vehicle scheduling problem", Highway Engineering, vol. 34, no. 6, pp. 68-75, 2009

[12] X. Zuo, C. Chen, W. Tan, and M.C. Zhou, "Vehicle scheduling of an urban bus line via an improved multiobjective genetic algorithm," IEEE Transactions on Intelligent Transportation Systems, vol. 16, no. 2, pp. 1030-1041, 2014.

[13] I. Steinzen, M. Becker, and L. Suhl, "A hybrid evolutionary algorithm for the vehicle and crew scheduling problem in public transit," 2007 IEEE Congress on Evolutionary Computation, Singapore, pp. 3784-3789, 2007.

[14] N. Jozefowiez, F. Semet, and E.G. Talbi, "An evolutionary algorithm for the vehicle routing problem with route balancing," European Journal of Operational Research, vol. 195, no. 3, pp. 761-769, 2009.

[15] L. Caggiani and M. Ottomanelli, "A dynamic simulation based model for optimal fleet repositioning in bike-sharing systems", Procedia-Social and Behavioral Sciences, vol. 87, pp. 203-210, 2013.

[16] M.J. Wu, H.Z. Dong, D.X. Liu, and N. Chen, "Research on the dynamic model with multi-objective and algorithm for public bicycle rebalancing problem", Mechanical \& Electrical Engineering Magazine, vol. 32, no. 7, pp. 1006-1010, 2015.

[17] J.G. Zhang, T. Wu, and Y.S. Jiang, "Study on scheduling algorithm for public bicycle system based on ant colony algorithm", Journal of Xihua University, vol. 33, no. 3, pp. 70-76, 2014.

Pinhong Zeng, a lecturer of Faculty of Economics and Business Administration, Yibin University, got her master's degree in the Business School of Sichuan University. Her main research field is economic development and management. She has published more than ten academic articles.

\section{Creative Commons Attribution License 4.0 (Attribution 4.0 International , CC BY 4.0)}

This article is published under the terms of the Creative Commons Attribution License 4.0 https://creativecommons.org/licenses/by/4.0/deed.en_US 